\title{
Meteorological and oceanographic situation in the German Bight from 23 to 29 April 1991
}

\author{
Corinna Schrum ${ }^{1, *}$, Peter König ${ }^{2}$, Kirsten Michaelsen ${ }^{3}$, Ulrike Niemeier ${ }^{3}$, \\ Thomas Pohlmann ${ }^{1}$
}

\author{
'Zentrum für Meeres- und Klimaforschung der Universität Hamburg, Institut für Meereskunde, Troplowitzstr. 7 , \\ D-22529 Hamburg, Germany \\ ${ }^{2}$ Bundesamt für Seeschiffahrt und Hydrographie, Bernhard-Nocht-Str. 78, D-20359 Hamburg, Germany \\ ${ }^{3}$ Zentrum für Meeres- und Klimaforschung der Universität Hamburg, Institut für Meteorologie, Bundesstr. 55 , \\ D-20146 Hamburg, Germany
}

\begin{abstract}
The meteorological and oceanographic situation during a $6 \mathrm{~d}$ drift experiment in the German Bight at the end of April 1991 is evaluated by combining field data, observation network data and results of different numerical models. By combining all available data, it was possible to represent the complex state of the physical situation during the course of the drift experiment and to gain essential information for the interpretation of chemical and biological measurements performed during the drift experiment. This examination shows that the drift experiment can be subdivided into 2 parts. During the first part the situation was dominated by a high pressure system over Scandinavia. This high was associated with weak easterly winds which transported polluted air masses into the region of the experiment. The prevailing easterly winds led to a strong vertical shear in the oceanic circulation between the upper water levels. This shear caused water masses of different origin to coincide within the drift experiment region. During the second phase the region was influenced by a low which led to precipitation and thereby to a washout of contaminants from the atmosphere. Under the influence of the prevailing northerly winds during the second phase, the vertical shear of the oceanic circulation diminished and a cyclonic circulation established itself over the whole water column, as model results showed.
\end{abstract}

KEY WORDS: North Sea - German Bight - Drift experiment - Numerical modelling

\section{INTRODUCTION}

As part of the German research project PRISMA, several multi-ship cruises were undertaken between 1991 and 1993 to evaluate transformation processes of nutrients and contaminants in the German Bight. However, temporal development of contaminants and nutrients in the sea does not only depend on internal transformation processes. Atmospheric fluxes into the sea as well as transport in the water might change concentrations. The aim of a drift experiment is to minimize the influence of advection in the sea and to study processes in a nearly homogeneous water body. Nevertheless, a drift experiment results in an investi-

•E-mail: schrum@dkrz.de gation in a homogenous water body only if no shear is present, which is normally not the case in the ocean. Thus, for understanding and investigating the processes of transformation involved, evaluation of the meteorological and oceanographic situation during a drift experiment is a basic requirement.

A central part of the PRISMA cruise in 1991 was a 1 wk drift experiment in the northwestern part of the German Bight (the course of the drifter and a detailed description of the experiment strategy are given by Brockmann et al. 1997 in this volume) from 23 to 29 April, in which the RV 'Valdivia' followed a drifting buoy, while RV 'Gauss' carried out measurements on a rectangular grid covering most of the German Bight. The SWSRV 'Atair' deployed and maintained several moorings north of Helgoland. The data set for the meteorological and oceanographic parameters in the 
drifter area is comprehensive; it is incorporated in the relatively coarse measuring grid of the German Bight. However, the data base from observations only is not sufficient for a detailed evaluation of the physical state and underlying dynamic processes. On account of this, the additional support of validated numerical models was used for interpretation of the meteorological and oceanographic situation.

\section{METEOROLOGICAL SITUATION}

\section{Data sources}

A number of meteorological measurements were performed near the actual positions of the drifting buoy. Automatic recording of wind velocity and wind direction at the sea surface was carried out every 10 min by RV 'Valdivia' At several locations in the German Bight rawinsondes were launched from RV 'Gauss' and manual readings of the meteorological parameters including wind direction, wind velocity, air/sea surface temperature, humidity and pressure were recorded every hour. Moreover, observations of cloud type and cloud cover were made on RV 'Gauss'. Information about precipitation is available for the positions of both ships.

Additional meteorological data on the large-scale and mesoscale situation were routinely provided by the meteorological observation network and prepared by the 'Deutscher Wetterdienst, Seewetteramt Hamburg'. By processing these data with an analysis model (Fig. 1 shows the extent of the model area; Luthardt 1987), near-surface values of wind, air pressure and air temperature on a rectangular grid in the region of the North Sea and its near surroundings were obtained. An analysis scheme was included to test the consistency of irregularly spaced observations and their temporal changes. The model distinguishes between observations over land and over sea

From gridded wind and pressure data of the analysis model, backward trajectories for the air flow were calculated (Fig. 1). Furthermore, the data from the model were used to force the oceanographic models discussed in the next section.

The grid resolution of $42 \mathrm{~km}$ determines the limit of resolution of the model results. For more detailed information in the investigated region, results of the mesoscale meteorological model METRAS (MEsoscale TRAnsport and Stream model; Schlünzen 1988, 1991) were taken into account. This model is based on the full equations of momentum, temperature, and humidity and calculates these variables prognostically. The METRAS model results (resolution of $5 \mathrm{~km}$ ) give an impression of the fine structure of the flow pattern which cannot be resolved by the measured data alone. However, model calculations with the METRAS model are time consuming and thus only possible for individual days. A description of the initialisation of the model for the PRISMA experiment is given by Schlünzen et al. (1997 in this volume).

\section{Measurements and model results during the drift experiment}

\author{
Large-scale meteorological situation
}

The meteorological situation during the experiment was mainly governed by easterly winds, which are common at this time of the year. Pressure, humidity, precipitation and temperature were close to the mean monthly values of the previous $4 \mathrm{yr}$.

During 16 and 17 April, before the beginning of the drift experiment, strong winds from the NNW caused intense vertical mixing of the water. Also, on the 22 nd a small low pressure system caused still stronger winds from the NW and precipitation. The low pressure system moved east during the night of 23-24 April, and during the first half of the drift experiment, from 24 to 27 April, the weather situation was dominated by a high pressure system over Scandinavia which initially caused weak, easterly near-surface winds over the region of the German Bight (Fig. 2). The high pressure system was stable until the $26 \mathrm{th}$, and in the area of the German Bight almost no precipitation was observed. The situation changed on 27 April, when a low pressure system in the upper troposphere moved into the area of the German Bight, and during the last period of the drift experiment the weather in the region of the German Bight was determined by this low.

\section{Mesoscale meteorological situation}

The time series of the observed wind direction near the position of the drifter (Fig. 3) shows that between 24 and 27 April the wind direction changed every day from $\mathrm{E}$ in the early morning to $\mathrm{NE}$ and $\mathrm{N}$ in the afternoon. The results of the mesoscale meteorological model give insight into this process. A model experiment for 24 April shows that the differential heating of the air over land and sea led to a temperature difference of up to $6 \mathrm{~K}$ in the afternoon, and, consequently, to a deflection of the near-surface wind parallel to the coast (Fig. 4). This effect occurred in a narrow near-coastal region, while the direction of the large-scale flow field over Denmark and the Baltic was still eastwards (Fig. 2). A comparison of the calculated wind and temperature distributions at 09:00 and 18:00 h UTC shows that the 

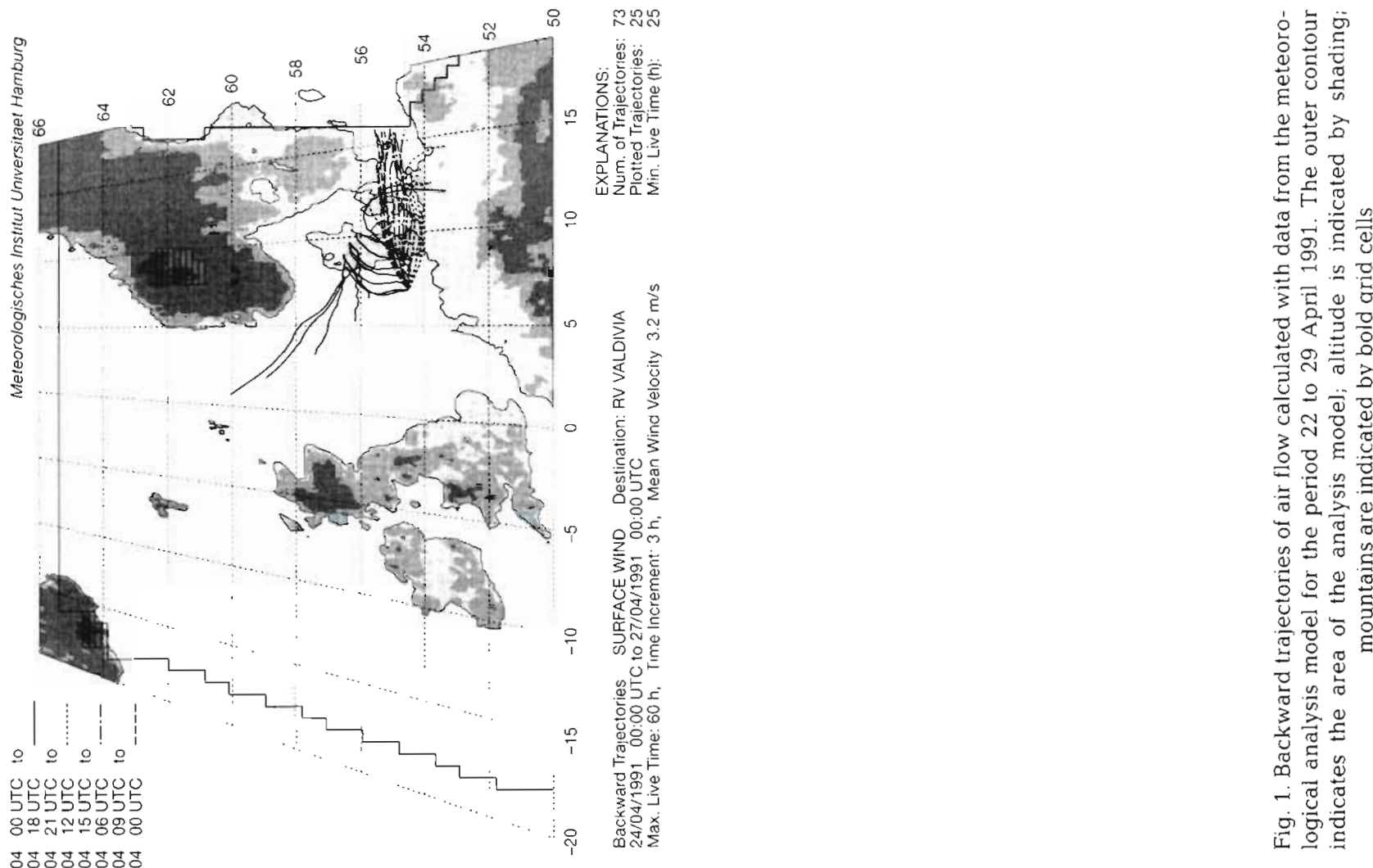

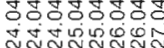
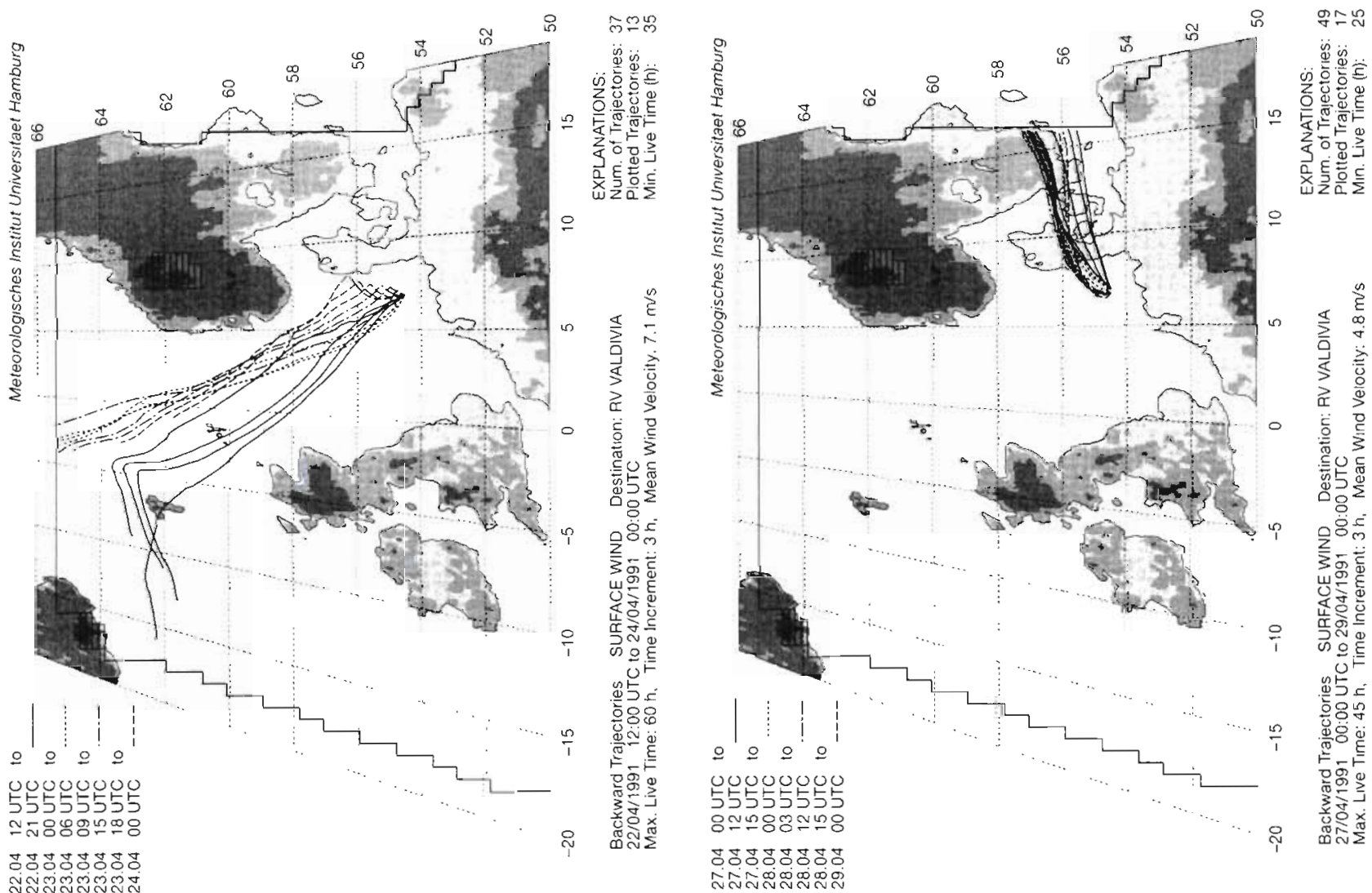


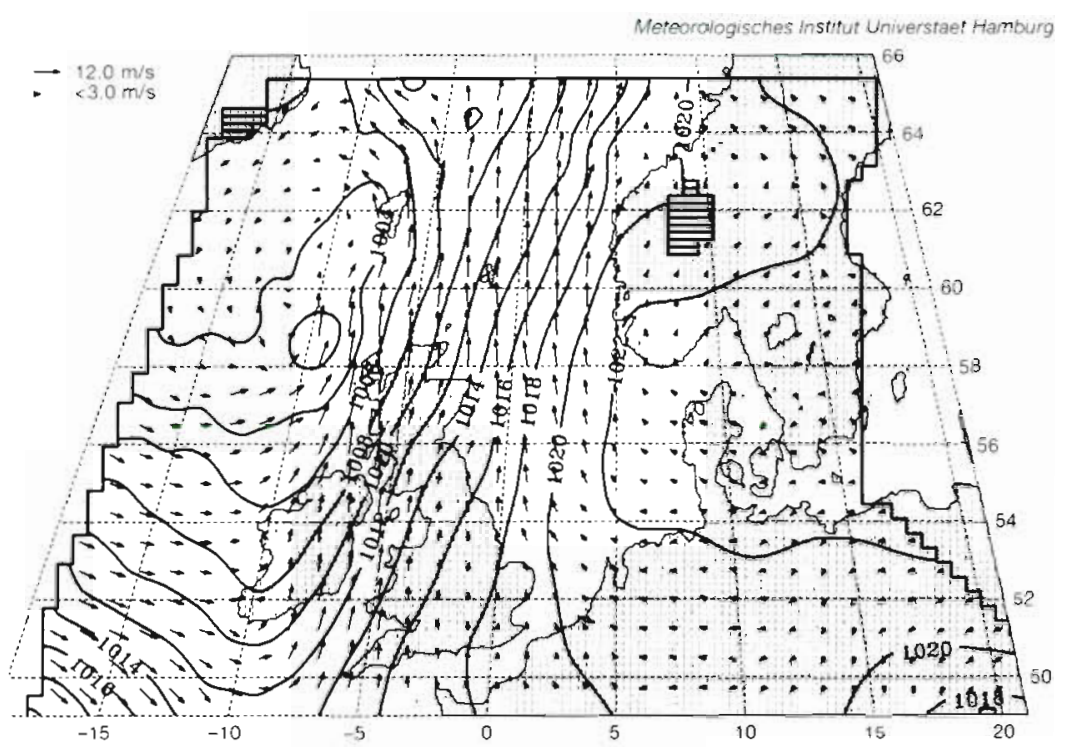

Fig. 2. Near-surface wind and air pressure (hPa) for 24 April, 12:00 h UTC; reanalysed observation data

\section{Atmospheric stratification and deposition}

The transport of contaminants in the atmosphere depends on wind speed, wind direction and on atmospheric stratification. In Fig. 1, backward trajectories from 22 to 29 April are presented. The maximum lifetimes of the trajectories are $60 \mathrm{~h}$. During the beginning of the drift experiment the pattern of backward trajectories indicated transport of less polluted air masses of North Atlantic origin to the drift area. That, in combination with precipitation, which was observed in the German Bight before the beginning of the experiment (see 'Large-scale meteorological situation; above), might account for the fact that high pollution concentrations in the air were not measured at the beginning of the drift experiment (Schlünzen et al. 1997).

The wind turned to the east during the night of 23-24 April and caused a transport of air from densely populated regions into the drift area. The profiles gained by the rawinsonde ascent above RV 'Gauss' for 24 April at 10:00 h UTC (Fig. 5) show a slightly stable stratification of the atmosphere and an inversion at $1700 \mathrm{~m}$. This inversion and the stable stratification prevented vertical exchange in the atmosphere, and thus anthropogenic contaminants remained in the lower parts of the atmosphere, which led to increasing measured concentrations of contaminants (Schlünzen et al. 1997).

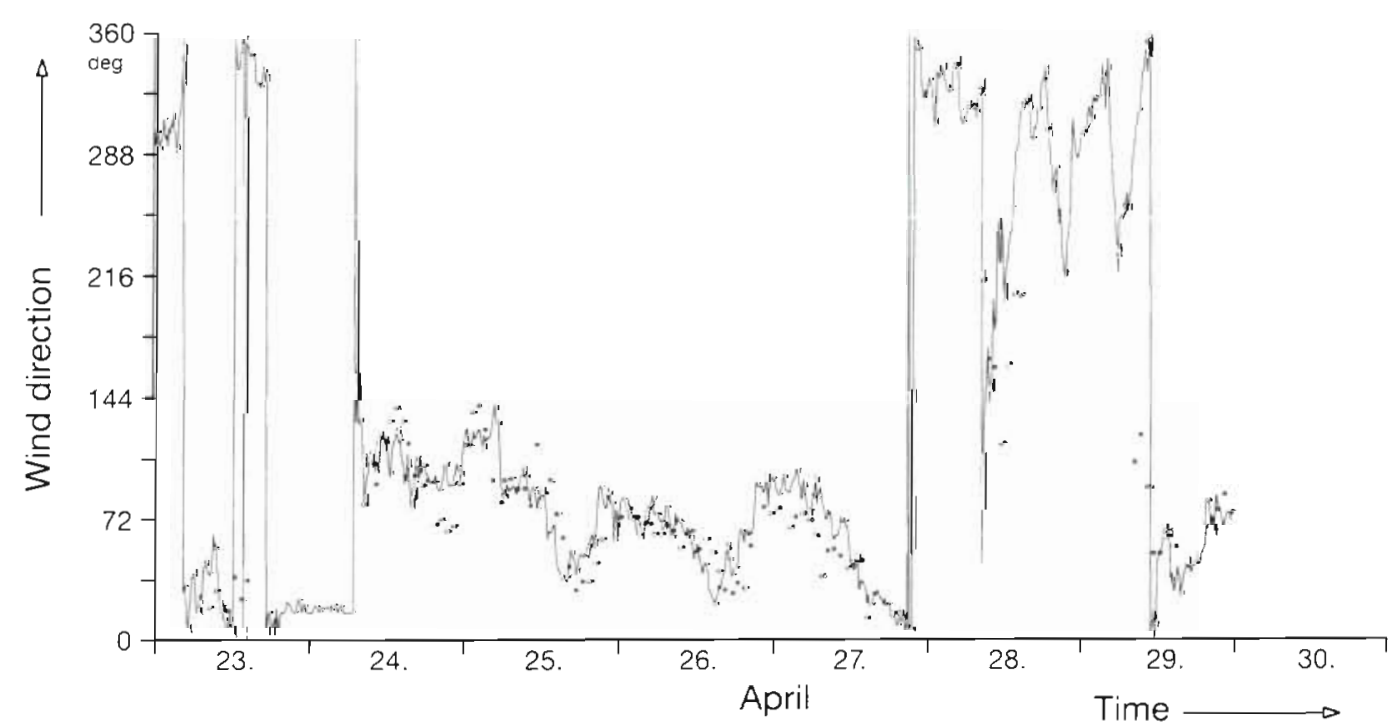

Fig. 3. Time series of the observed wind direction at RV 'Valdivia' (line) and at RV 'Gauss' (dots) during the drift experiment 

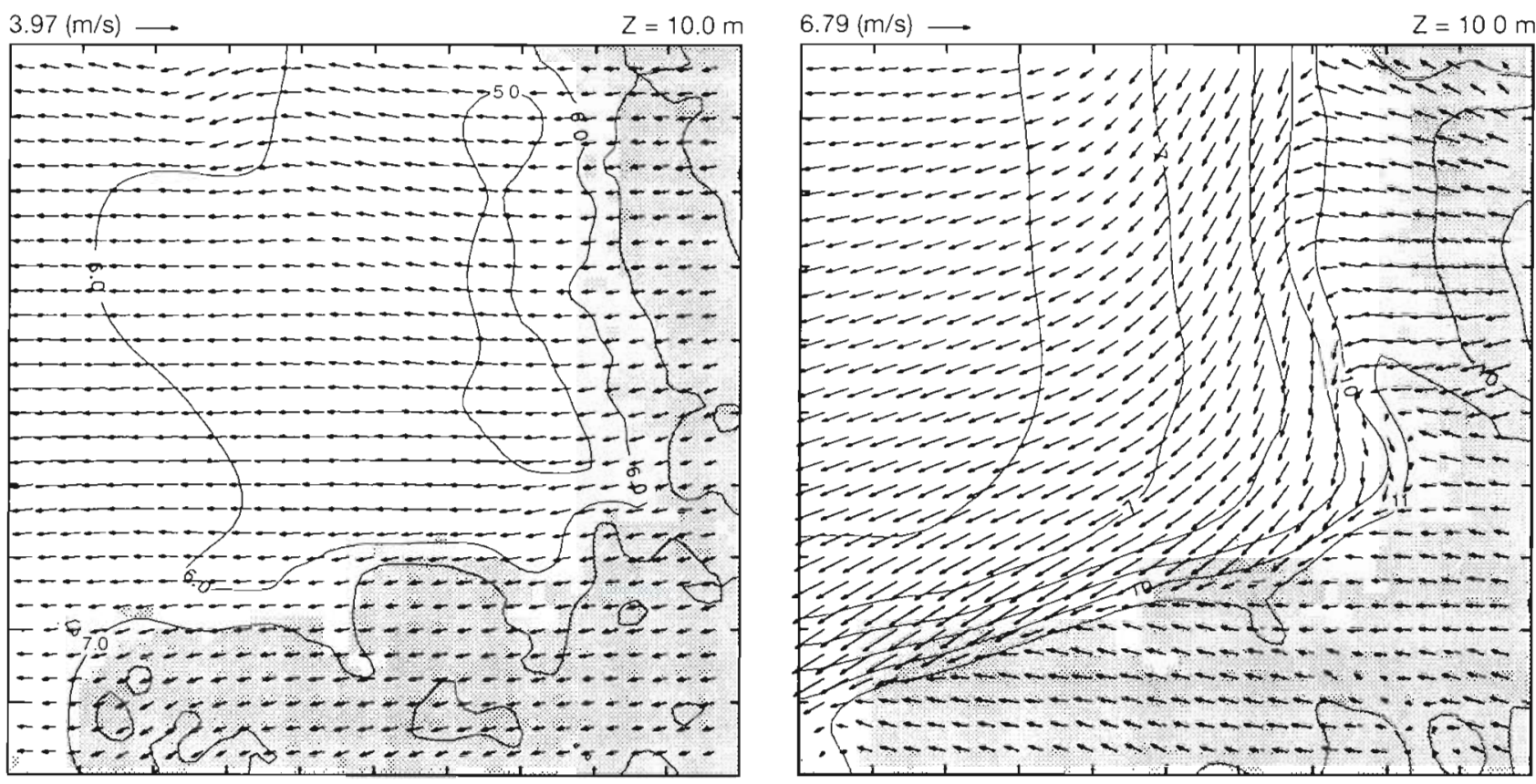

Fig. 4. Near-surface wind and air temperature $\left({ }^{\circ} \mathrm{C}\right)$ calculated with the METRAS model for 24 Aprl 1991 Left $09.00 \mathrm{~h}$ UTC, nght. $18.00 \mathrm{~h} \mathrm{UTC}$

During this time only high clouds were observed and no precipitation occurred, and thus no washout of the contaminants was possible. During the next $2 \mathrm{~d}$, the observed inversion diminished slowly and vertical exchange of contaminants in the atmosphere became possible, which could have been responsible for the observed decrease in concentrations during 25 April. Dry deposition, which is considerably smaller than wet deposition, could not have caused significant decrease of contaminants in the atmosphere during this short period. For the drift experiment the total wet deposi- tion, which was caused by a single rain event of $5 \mathrm{~h}$ duration, was 10 times larger than the dry deposition during the experiment (Schlunzen et al. 1997).

The vertical profile of the rawinsonde ascent for 27 April shows a slightly unstable atmospheric stratification up to a strong inversion at $650 \mathrm{~m}$ height (Fig. 5). Due to high humidity of more than $80 \%$ to a height of $2000 \mathrm{~m}$ and unstable stratification, rain clouds occurred over the German Bight Precipitation and fog were observed adjacent to the drift region during the last $3 \mathrm{~d}$ of the drift experiment.
Fig. 5. Profiles of the rawinsonde ascents from RV 'Gauss' for 24 April (solid lines) and 27 April (dashed lines). $R$ : relative humidity; $T$ : temperature $_{i}$ ff: wind speed; $d d$ : wind direction; $\Theta$ : potential temperature

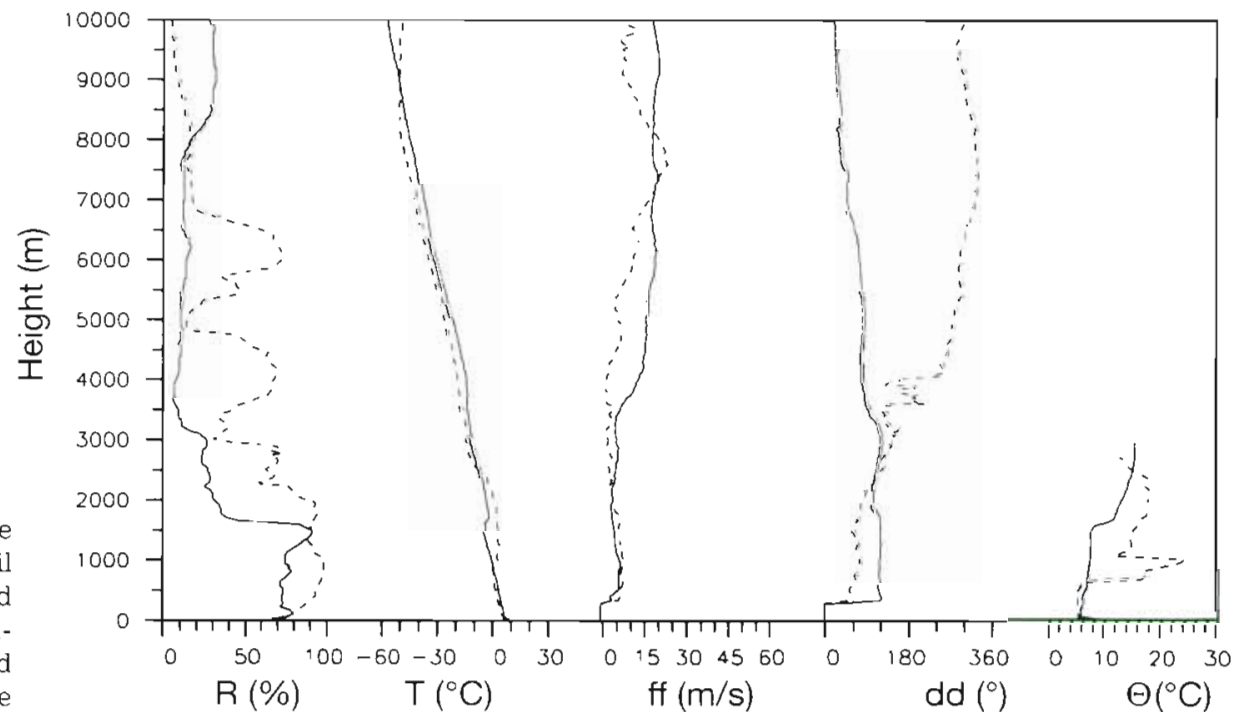


During the second part of the experiment, washout of contaminants and humid deposition was possible Therefore, and due to vertical exchange in the lower atmosphere the high concentrations of anthropogenic contaminants in the air decreased (Schlünzen et al. 1997). However, the wet deposition in combination with the transport of polluted air from Eastern Europe between 26 and 29 April led to high inputs of contaminants into the water masses surrounding the drifter (Schlünzen et al. 1997).

The calculated backward trajectories for the period from 26 to 29 April are sometimes cut off at the eastern boundary of the grid because the analysis model is based on the data of the North Sea region, and weather stations from Eastern Europe are not included in the model. Therefore, it is difficult to estimate the origin of air masses for the last period of the experiment. But estimates on the basis of meteorological observations charts (Anonymous 1991a, b) led to the assumption that air masses found from the 26th to the 29th were of continental origin from northeastern Europe.

\section{OCEANOGRAPHIC SITUATION}

In the German Bight, the response of oceanic circulation to wind forcing is immediate, within 1 tidal period, as reported previously by Backhaus (1980) and Dippner (1993). Therefore, any discussion of the oceanographic situation must be related to the corresponding meteorological situation.

\section{Oceanographic measurements}

During the drift experiment, CTD profiles and water samples were taken 4 times a day both near the drifter and at 3 surrounding positions, each 3 nautical miles away. These measurements were carried out by RV 'Valdivia'. Time series of hydrographic parameters are discussed by König \& Schrum (1997 in this volume).

As explained edrlier, the drift experiment was only one part of the PRISMA field campaign in April 1991. The participating research vessels carried out a variety of further oceanographic measurements during their 2 wk cruises. RV 'Gauss' measured salinity, temperature and other parameters on a rectangular grid while SWSRV 'Atair' carried out current measurements at 6 locations in the German Bight.

The aim of this measurement strategy was to gain as much information as possible about the oceanographic environment during the drift experiment. However, a comprehensive picture of currents and transports in the sea is not provided, since the available measure- ments only yield information at 6 selected positions and in not more than 3 depth layers. To examine the large- and mesoscale oceanographic situation and circulation, model results were used. The large-scale situation was evaluated with a hydrodynamic North Sea model (Backhaus et al. 1991, Pohlmann 1996a), while the mesoscale situation was examined with an eddy-resolving model of the German Bight (Schrum 1994, 1997).

\section{North Sea model}

The physics of the North Sea model have been described earlier by Pohlmann (1996a). Here, only a short outline of the model will be given. The model is a modified version of HAMSOM (HAMburg Shelf Ocean Model), a fully nonlinear baroclinic circulation model with a horizontal grid resolution of 1.2 nautical miles. The vertical grid resolution is $5 \mathrm{~m}$ within the upper $50 \mathrm{~m}$. The lower layers have thicknesses from $10 \mathrm{~m}$ up to $400 \mathrm{~m}$. The model results have been verified by a comparison with the FLEX data set (Pohlmann 1996a). In earlier studies the model has proved to provide reliable information about thermal stratification and vertical eddy viscosity on a basinwide scale (Pohlmann $1996 \mathrm{~b}, \mathrm{c})$.

The tidal forcing of the model consists of 8 tidal constituents which are prescribed at the open boundaries. For the atmospheric forcing, time-dependent surface wind stress and air pressure fields are prescribed. Here, the model uses the gridded information produced by the analysis model described above ('Data sources'). Time-dependent values for the sea surface temperature (SST) are prescribed. The data are taken from weekly SST charts (Becker et al. 1986) for the North Sea. These charts are compiled using SST observations from research vessels, merchant trading vessels and routine observations at oceanographic stations.

In a fully prognostic baroclinic simulation the model calculated the horizontal and vertical transport velocities, the temperature and the salinity for the period from July 1990 to April 1991.

\section{German Bight model}

The German Bight model is an application of HAMSOM. A brief outline of the model physics has been given by Schrum $(1994,1997)$. Therefore, only some basic information about the calculations and the general model concept will be given. The horizontal grid distance of the model is 1.5 nautical miles, and in the vertical direction the model has a constant resolution 
of $5 \mathrm{~m}$. Temperature, salinity and surface elevation at the open boundaries to the North Sea are obtained from the North Sea model. At the estuaries of the rivers Elbe, Weser and Ems, a freshwater inflow is prescribed.

At the sea surface, the heat flux between atmosphere and ocean is calculated by summing up sensible and latent heat flux, global radiation and longwave radiation. The components are determined by using bulk formulae for the sensible and latent heat fluxes according to Kondo (1975), for the longwave radiation according to Berliand \& Berliand (1952) and for the global radiation according to Dobson \& Smith (1988). These bulk formulae have successfully been used by Radach \& Moll (1993) for the North Sea and by Moll \& Radach (1991) for the German Bight. The information about air temperature, dewpoint temperature and cloudiness which is necessary for calculating heat fluxes is obtained from the meteorological observation network of the 'Deutscher Wetterdienst, Seewetteramt Hamburg'.

Similarly to the North Sea model, boundary conditions of wind stress and surface pressure are derived from gridded data of the analysis model outlined above.

The hydrodynamic model of the German Bight has been verified by a detailed comparison with measurements during the experiment in April 1991. A brief description of this comparison was given by Schrum (1994). The verification shows a good correspondance between measured and computed temperatures at the locations of the 6 moorings. The discrepancy at all 6 positions lies below $0.5 \mathrm{~K}$ for the whole period of data collection.

The correspondence between simulated and measured salinities is good with respect to the overall structures and trends, but the absolute magnitude of the computed salinity is smaller than the observed salinity. One reason for this deviation is the high positive salinity anomaly during 1990 and 1991 (Becker \& Dooley 1995) which cannot be resolved adequately in the model results, as the computation for April 1991 started from a climatological mean distribution.

The local comparison of measured and modelled current velocities at the position of a mooring $15 \mathrm{~km}$ away from the drift area shows a good agreement of calculated and observed velocity directions. However, disturbances with time scales $<3 \mathrm{~h}$ were not reproduced. The pattern of the magnitude of velocity was reproduced well.

\section{Observations and model results}

The temperature distribution corresponds to the seasonal heating and advective processes in the German Bight. Satellite and shipborne observations show a local temperature minimum in the region west and northwest of Helgoland (Fig. 6), where surface water temperatures below $6^{\circ} \mathrm{C}$ were observed. This minimum is visible for the whole period of the drift experiment. The reason is revealed by a closer look at the circulation system in the German Bight. For this purpose, results of the numerical North Sea model and the German Bight model will be used. In the following, the circulation will be discussed on the basis of the calculated daily mean surface currents and the calculated daily mean stream function (Fig. 8).

Fig. 7 shows backward trajectories at the surface and at $25 \mathrm{~m}$ depth calculated with the daily mean velocity fields produced by the North Sea model. Their paths

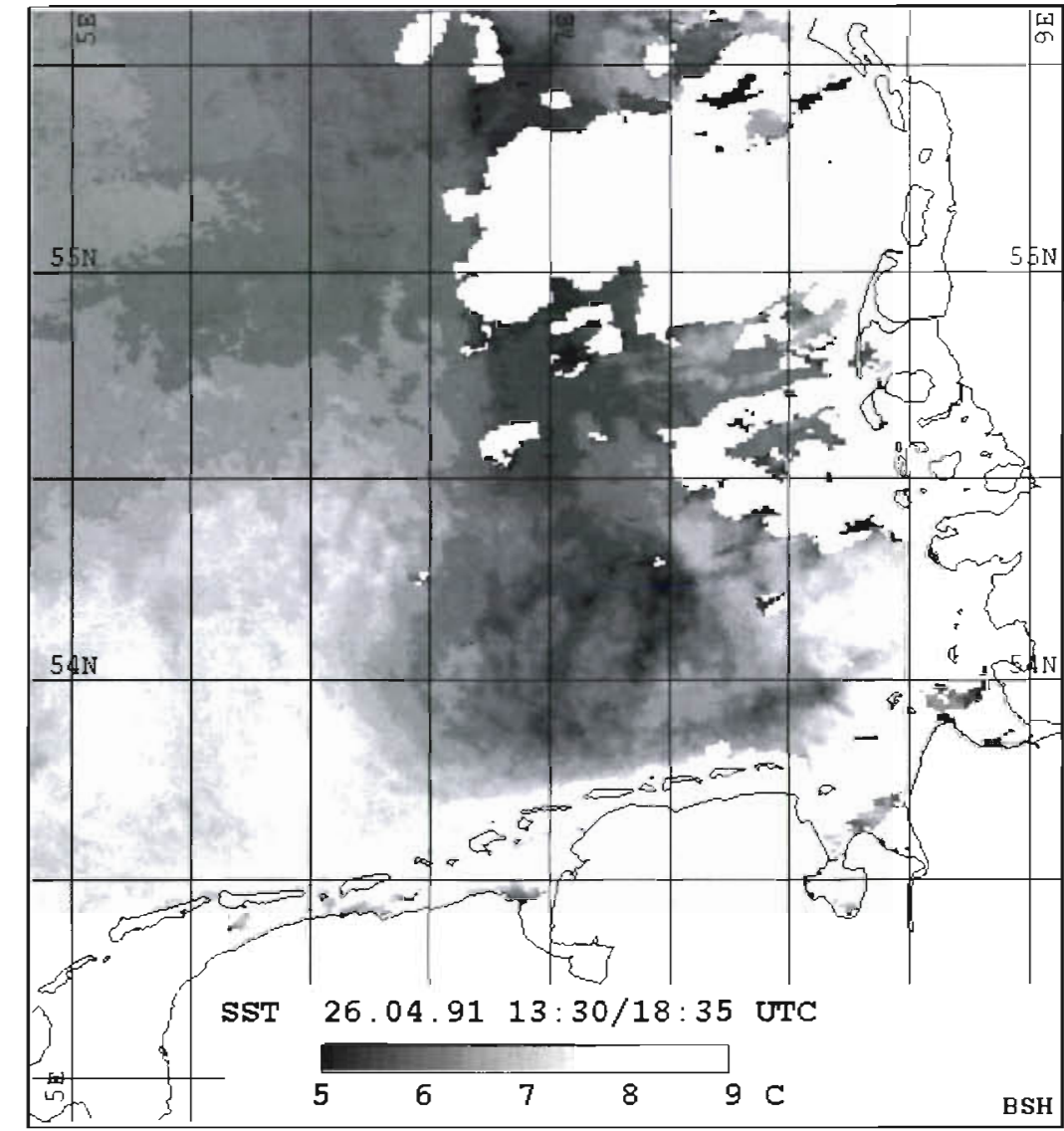

Fig. 6. NOAA-10 and NOAA-11 satellite sea-surface temperature for 26 April 1991, composed from 2 views at 13:30 and 18:35 h UTC 

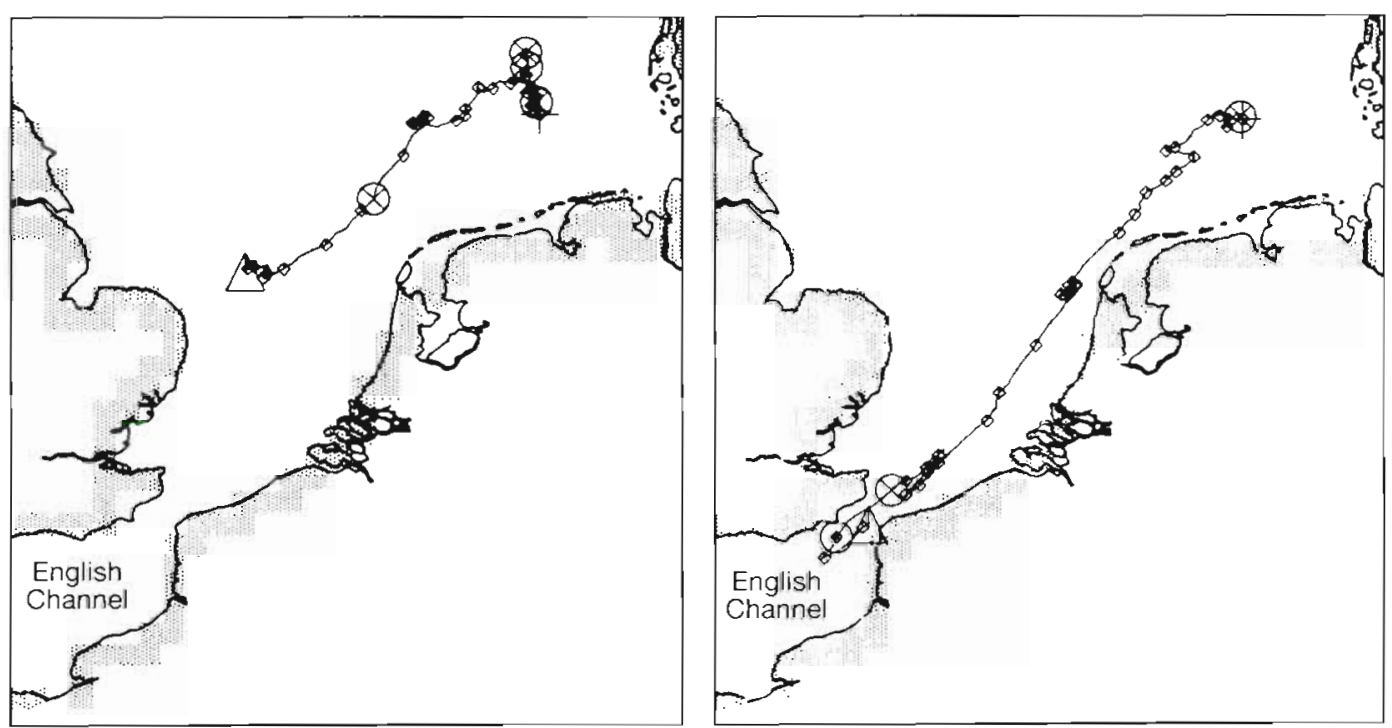

Fig. 7. Backward trajectories calculated from the North Sea model for the period from 1 November 1990 to 27 April 1991 , at $25 \mathrm{~m}$ depth (left) and for the surface layer (right). The triangle marks the starting positions on 1 November, and the plus symbols the end position, i.e. the drifter position on 27 A pril. Upwelling into the next model layer is marked by a circle with a cross and downwelling into the next layer by a circle with a dot in the center. The weekly positions are marked with a diamond. The grey shaded line along the coastline represents the model grid coastline of the North Sea model

give an impression of the origin of water masses at the drifter position. Accordingly, water masses show different positions of origin for different arrival depths. Water masses found in lower layers originate further north than those found in upper layers, which originate from the English Channel.

It is not possible to obtain detailed insight into the circulation in the German Bight during the drift period using the large-scale North Sea model. Here, the results of the fine-resolution model are necessary.

Before the drift experiment started, mean winds from the west or northwest were observed in the region of the German Bight. The resulting circulation at the beginning of the drift experiment was cyclonic and showed transport over the western boundary and a deep outflow in the northwestern direction. Weak surface velocities could be observed in the region of the post-glacial Elbe River valley and near the North Frisian coast. The wind-induced near-surface transport and the baroclinic transport acted in opposite directions and led to a minimized surface circulation, which is typical for westerly winds (Schrum 1994).

During the first phase of the drift experiment from 24 to 27 April, the prevailing easterly winds caused a different circulation. The vertically averaged circulation changed from cyclonic to anticyclonic in the region of the post-glacial Elbe River valley (Fig. 8, bottom panel), which is equivalent to a net mass transport over the northern boundary into the German Bight and a net outflow over the western boundary. At the northeastern boundary of the post-glacial Elbe
River valley, near the $30 \mathrm{~m}$ depth contour, a cyclonic recirculation is calculated. The surface transport diagram (Fig. 8, top panel) shows a cyclonic circulation near Helgoland and a near-surface transport to the northwest, directed opposite to the vertically averaged transport. This points to a strong deep inflow and a strong vertical shear in the transport field between the upper depth layers. The near-surface outflow and the inflow in lower layers caused upwelling for reasons of continuity, and due to upwelling, vertical mixing in the region of the post-glacial Elbe River valley takes place. This upwelling is responsible for the observed local temperature minimum west of Helgoland (Fig. 6).

Southeast of the upwelling region, thermohaline stratification occurred, while the near-surface outflow and the inflow at greater depths led to transport of lighter, warmer and less saline water over colder and more saline water (Fig. 9). The haline stratification caused by wind-induced advection allowed the development of a thermocline even near the coast, in regions where tidal stirring is high (Schrum 1997); thus vertical exchange was inhibited.

At the beginning of the drift experiment the drifter was east of the upwelling region at the border of the stratified region, and a weak thermocline was observed at the position of the drifter (Fig. 10). During the last $3 \mathrm{~d}$ the drifter was located inside the upwelling region where no thermocline could be observed (König \& Schrum 1997 and Figs. 9 \& 10).

In the beginning of the second phase of the drift experiment the change in wind direction to northerly 
directions caused an immediate response of the ocean. Until the end of the drift experiment a cyclonic vertically averaged circulation and a cyclonic surface circulation were observed. The inflow in the central layers of the water column changed to an outflow directed to the northwest, while the surface circulation hardly changed at all and the strong vertical shear in the transport field disappeared. The vertically averaged transport directed to the northwest led to less saline water in the region of the drift experiment.

\section{SUMMARY AND CONCLUSIONS}

The PRISMA drift experiment can be subdivided into 2 phases. The first days were dominated by a high pressure area in the experimental region. Weak easterly winds transported polluted air masses into the German Bight. On 24 April the stratification of the atmosphere was somewhat stable and showed an inversion which inhibited vertical exchange and led to an accumulation of anthropogenic contaminants in the lower layers. This caused high nearsurface concentrations of anthropogenic contaminants, but lower concentrations in the upper atmosphere were possible.

During the second phase of the drift experiment, the region was influenced by a low connected to precipitation and cloud cover. The weak, unstable stratification within the lower atmosphere enabled vertical exchange. Observed concentrations of contaminants in bottom layers decreased (Schlünzen et al. 1997). This is nevertheless not equivalent to a low content of contaminants in the atmosphere; vertical exchange merely reduces the near-surface concentrations. Further reasons for decreasing concentrations are the washout through precipitation and humid deposition which occurred during the second phase of the drift experiment.

During the first phase of the drift experiment, the water circulation was mainly caused by the prevailing easterly winds. Typical features during the easterly winds were an anticyclonic vertical
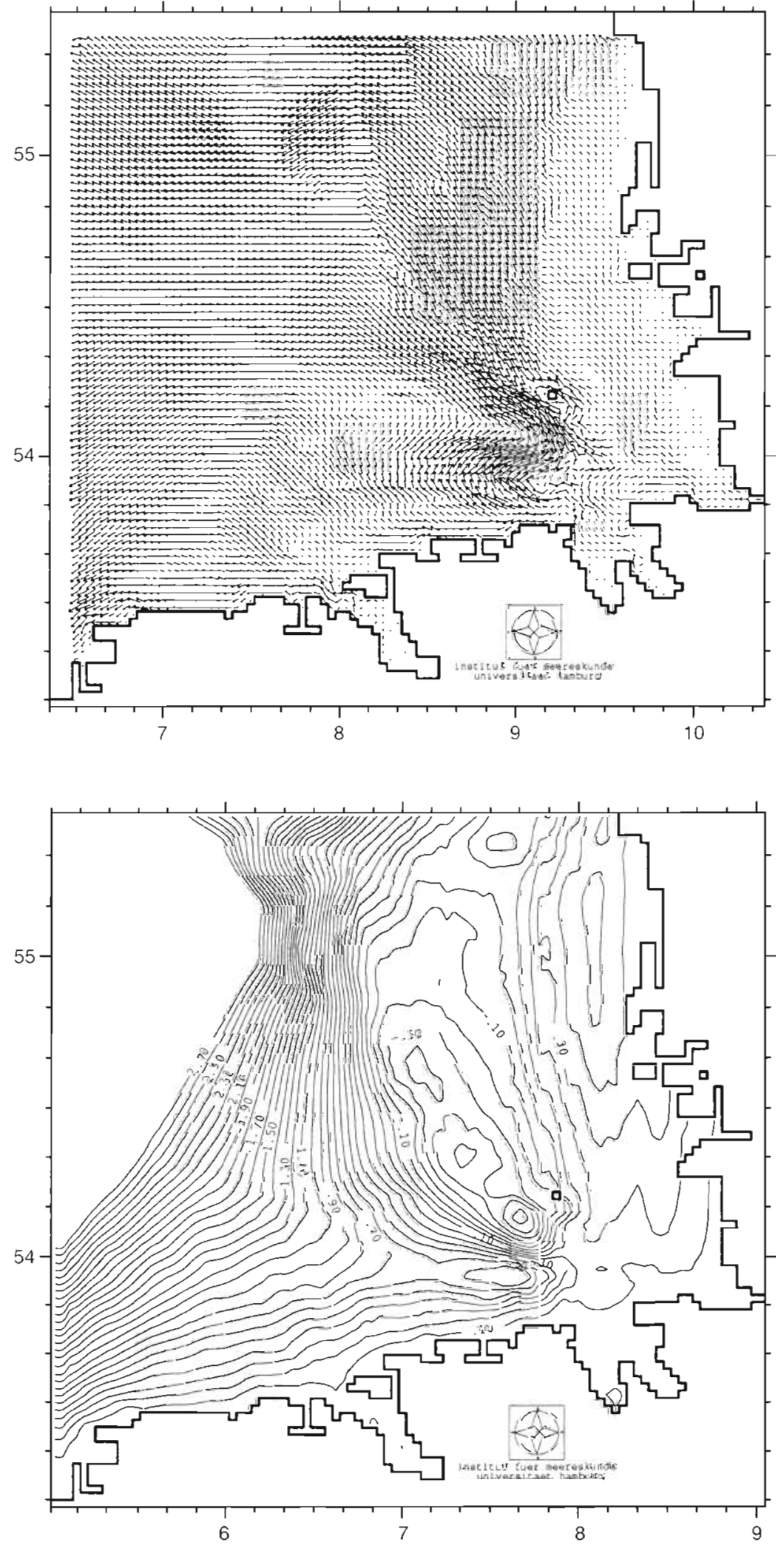

Fig. 8. Calculated surface transport (top panel) and stream function (bottom panel, contour interval $10^{4} \mathrm{~m}^{3} \mathrm{~s}^{-1}$ ) for 26 April 

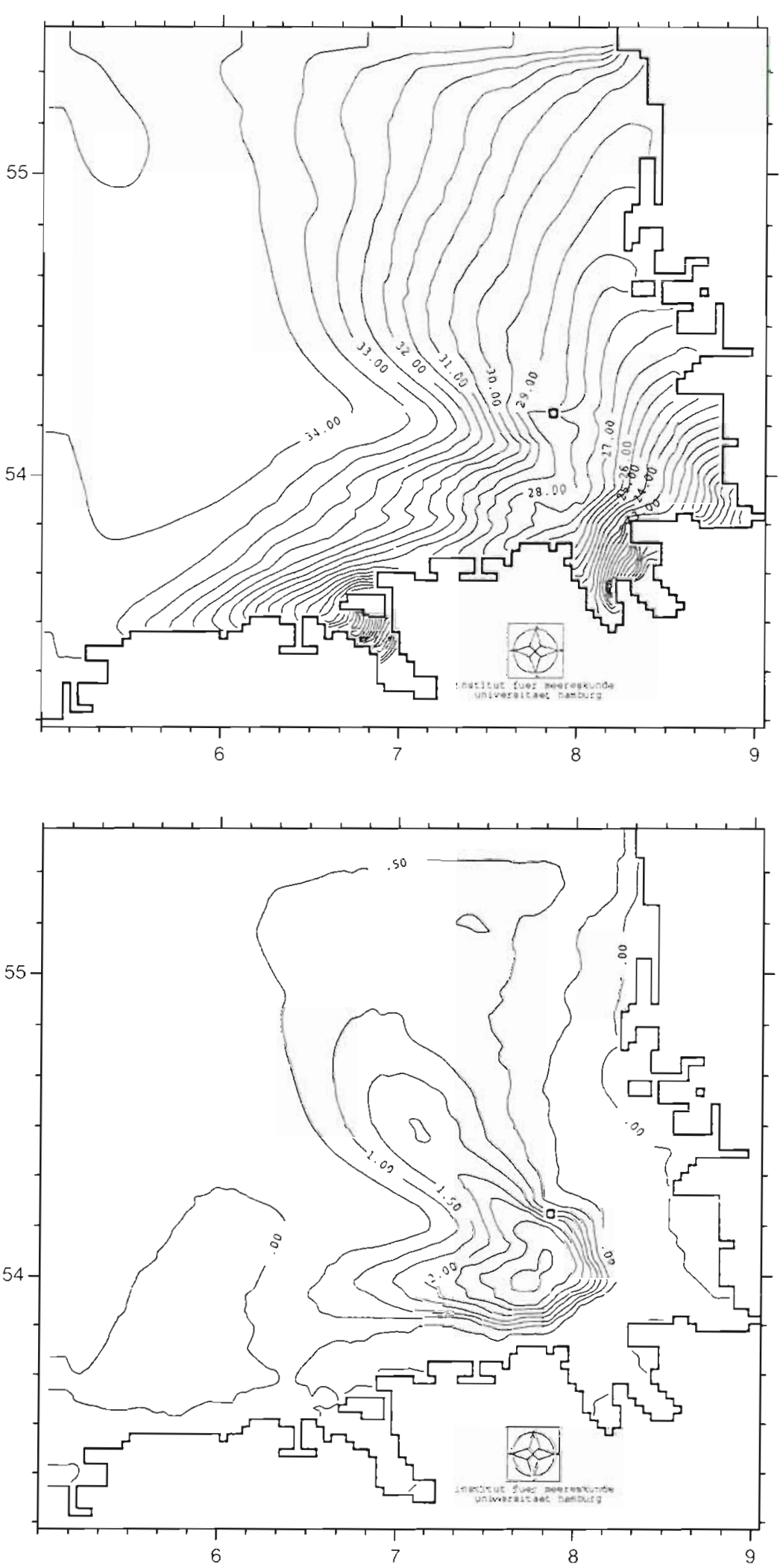

Fig. 9. Calculated surface salinity (top panel) and difference between surface and bottom salinity (bottom panel) in PSU for 26 April mean circulation and a cyclonic circulation in the surface layer, leading to a strong vertical shear in the upper layers of the water column. In the area of the drift experiment the transport in the surface layer pointed north-northwest, while the transport below proceeded in the opposite direction. The shear led to a coincidence of water masses of different origins.

The inflow in the lower layers and outflow in the upper layers caused upwelling in the region southwest of Helgoland, characterized by a vertically uniform temperature and salinity distribution. This vertical mixing led to a local temperature minimum and a local salinity maximum in the surface layer. East of this upwelling region thermohaline stratification developed, while near the coast a weak thermocline occurred, possibly due to haline stratification caused by advection.

The increasing wind velocities during the night of 26-27 April caused a growing near-surface transport of less salty coastal water to the northeast and therefore a weakening of the surface salinity front as well as a wider extension of the stratified region during the drift experiment. Because of the destruction of the haline front, exchange between coastal water and North Sea water could take place. This, in combination with wet deposition, could be one of the reasons for increasing contaminant concentrations in the water masses near the drifter.

The interdisciplinary framework and the combination of available field and model data resulted in a wealth of information about the state of the atmosphere and the sea. The experimental concept was able to explain most of the mesoscale variability on time scales of several hours and horizontal scales of several kilometers.

Future work is necessary for explaining mesoscale variability on time scales of less than several hours, which are not resolved by the models. There is a lack of knowledge about the physics which control this short-term variability. Further information about processes on these time scales could be obtained in 


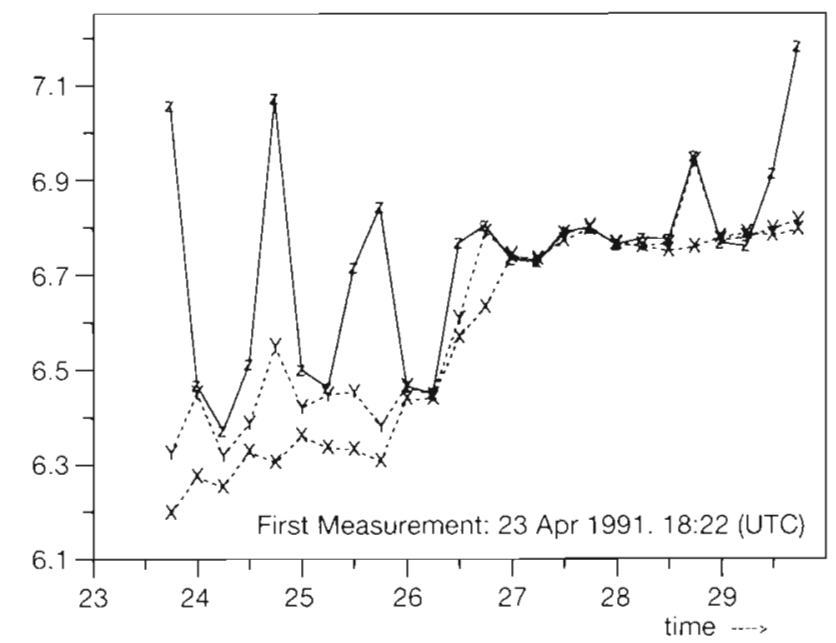

Fig. 10. Observed time series of temperatures $\left({ }^{\circ} \mathrm{C}\right)$ at the respective positions of the drifter at $5 \mathrm{~m}(\mathrm{Z}), 10 \mathrm{~m}(\mathrm{Y})$ and $30 \mathrm{~m}$ depth $(x)$

the future by coupling mesoscale meteorological and oceanographic models.

Acknowledgements. We thank M. Falke, now at the Umweltbehörde Hamburg, for making the meteorological measurements on board RV 'Gauss', A. Frohse, W. Lange and H. Klein for making the oceanographic measurements and the officers and crew of SWSRV 'Atair', who deployed the instruments. For maintaining the instruments we are grateful to $\mathrm{M}$. Stockhusen. Processing of the data was done with the help of I. Gottschalk. M. Kasianowski and K. Rogge. For calculating the backward trajectories and preparing some of the figures we thank $V$. Reinhard from the Meteorologisches Institut, Universität Hamburg. For revising the manuscript we are grateful to $\mathrm{Dr} H$. Langenberg and S. Beddig from the Institut für Meereskunde, Universität Hamburg. This work was funded by the Bundesministenum für Forschung und Technologie in Bonn under grant number 03F0558A1, the Universität Hamburg and the Bundesamt für Seeschiffahrt und Hydrographie.

\section{LITERATURE CITED}

Anonymous (1991a) Europäischer Wetterbericht. Amtsblatt des Deutschen Wetterdienstes, Offenbach

Anonymous (1991b) Berliner Wetterkarte. Meteorol Abh Ser B 66(4)

Backhaus JO (1980) Simulation von Bewegungsvorgängen in der Deutschen Bucht. Dtsch Hydrogr Z Erg-H Reihe B 15 Backhaus JO, Bartsch J, Damm P, Pohlmann T, Schrum C

This article was submitted to the editor
(1991) The marine weather bulletin North Sea. Int Counc Explor Sea CM 1991/C 16:1-17

Becker GA, Dooley H (1995) The High Salinity Anomaly in the North Sea and adjacent areas. Ocean Challenge 6(1):52-57

Becker GA, Frey H. Wegner G (1986) Atlas der Temperatur an der Oberfláche der Nordsee. Dtsch Hydrogr Z, Erg-H Reihe B 17:1-127

Brockmann UH, Raabe T, Nagel K, Haarich M (1997) Measurement stritegy of PRISMA: design and realisation. Mar Ecol Prog Ser 156:245-254

Dippner JW (1993) A frontal-resolving model for the German Bight. Cont Shelf Res 13(1):49-66

Dobson FW, Smith SD (1988) Bulk models of solar radiation at sea. Q J R Meteorol Soc 114:165-182

Kondo J (1975) Air-sea bulk transfer coefficients in diabatic conditions. Boundary-layer Meteorol 9:91-112

König P. Schrum C (1997) Hydrographic observations and model results from a PRISMA drift experiment. Mar Ecol Prog Ser 156:255-261

Luthardt $H$ (1987) Analyse der wassernahen Druck- und Windfelder über der Nordsee aus Routinebeobachtungen. Hamb Geophys Einzelschr A83

Moll A, Radach G (1991) Application of Dobson and Smith's solar radiation model to the German Bight data. Q J R Meteorol Soc 117:845-851

Pohlmann T (1996a) Predicting the thermocline in a circulation model of the North Sea. Part I: model description, calibration and verification. Cont Shelf Res 16(2):131-146

Pohlmann T (1996b) Calculating the annual cycle of the vertical eddy viscosity in the North Sea with a three dimensional baroclinic shelf sea circulation model. Cont Shelf Res 16(2):147-161

Pohlmann I (1996c) Calculating the development of the thermal vertical stratification in the North Sea with a three-dimensional circulation model. Cont Shelf Res 16(2): 163-194

Radach G, Moll A (1993) Estimation of the variability of production by simulating annual cycles of phytoplankton in the central North Sea. Prog Oceanogr 31:339-419

Schlünzen KH (1988) Das mesoskalige Modell 'METRAS' Grundlagen, Validierung, Anwendung. Hamb Geophys Einzelschr A88

Schlünzen KH (1991) Numerical studies on the inland penetration of sea breeze fronts at a coastline with tidally flooded mudflats. Beitr Phys Atmosph 63:243-256

Schlünzen KH, Stahlschmidt T, Rebers A, Niemeier U, Kriews M. Dannecker W (1997) Atmospheric input of lead into the German Bight-a high resolution measurement and model case study. Mar Ecol Prog Ser 156:299-309

Schrum C (1994) Numerische Simulation thermodynamischer Prozesse in der Deutschen Bucht. Ber Zentr MeeresKlimaforsch, Reihe B: Ozeanographie, 15

Schrum C (1997) Thermohaline stratification and instabilities at tidal mixing fronts. Results of an eddy resolving model for the German Bight. Cont Shelf Res 17(6):689-716

Manuscript received: January 2, 1997

Revised version accepted: June 2, 1997 